\title{
Fabrication and Electromagnetic Characterization of Novel Self-Metallized Thin Films
}

\author{
Anne I. Mackenzie \\ MS 473, Sensors Research Branch \\ NASA Langley Research Center \\ Hampton, VA, 23681-0001 \\ 757-864-1820 \\ a.i.mackenzie@larc.nasa.gov
}

Robin L. Cravey

757-864-1819

r.1.cravey@larc.nasa.gov

Kenneth L. Dudley

757-864-1783

k.1.dudley@larc.nasa.gov

Dion T. Fralick

757-864-8362

d.t.fralick@1arc.nasa.gov

\author{
Gilda A. Miner \\ 757-864-1475 \\ g.a.miner@larc.nasa.gov \\ Diane M. Stoakley \\ 757-864-4246 \\ d.m.stoakley@larc.nasa.gov
}

MS 227, Advanced Materials \& Processing Branch

NASA Langley Research Center

Hampton, VA, 23681-0001

MS 490, Electromagnetics Research Branch

NASA Langley Research Center

Hampton, VA, 23681-0001

Abstract-Unique, self-metallized films were investigated for deployable reflector antenna applications at L-band. Polyamic acid resins or soluble polyimides were doped with metal complexes, cast into films, and thermally cured. Each resulting film had a metallic layer on one side, adhering unfailingly to the polymer. Metallization was successful for silver or palladium in 3,3',4,4'-benzophenonetetracarboxylic acid dianhydride (BTDA) and 4,4'oxydianiline and for gold in BTDA and 2,2-bis[4-(4aminophenoxy)phenyl]hexafluoropropane (4-BDAF) or the space durable polyimide, 2,2-bis(3,4-dicarboxyphenyl)hexafluoropropane dianhydride and 4-BDAF (LaRC$\left.\mathrm{CP} 1^{\mathrm{TM}}\right)$. Reflectivity, transmissivity, and emissivity were determined, using an HP 8510 Vector Network Analyzer, to within 0.001 precision and accuracy. A custom-made test fixture/positioner, a thru-reflect-line calibration, and calculated reflection coefficients were used. The Ag film proved most suitable for further study, with 0.9957 reflectivity and 0.0042 emissivity. The Pd films were 0.89 reflective and 0.11 emissive; both Au films tested entirely transmissive. Transmission and scanning electron micrographs, S-parameters, and power coefficients are shown.

\section{TABLE OF CONTENTS}

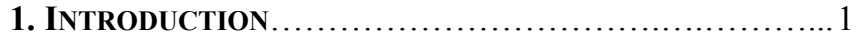

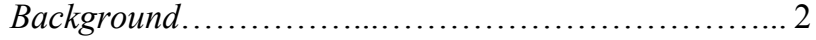

2. EXPERIMENTAL METHOD ............................... 3

Metallized Polymer Fabrication.......................... 3

Physical Characterization................................5

Electromagnetic Characterization........................ 5

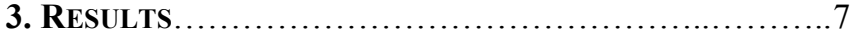

Physical Properties..................................... 7

TEM'S, SEM's, and Electromagnetic Properties........ 7

4. OBSERVATIONS AND CONCLUSIONS..................... 13

Quality of the Measurements............................ 13

Dependence of Emissivity on Frequency............... 13

5. FUTURE WORK....................................... 13

\section{INTRODUCTION}

NASA's Earth and Space Science programs have called for increasingly large, lightweight, deployable antennas for use in space. Antennas must be physically large (more than $10 \mathrm{~m}$ ) in order to achieve the accuracy and resolution required for microwave passive remote sensing of quantities such as ocean salinity and soil moisture. To make launching such large antennas into space feasible, designs that rely on using lightweight, packageable materials for the antenna surface have been proposed.

Metal meshes have found increasing use for research, military, and commercial purposes; a notable success has been NASA's Tracking and Data Relay Satellite System, with 4.8-m mesh reflectors in operation since 1983. The Highly Advanced Laboratory for Communications and Astronomy (HALCA) MUSES-B very-long-baseline interferometer, launched in 1997 with an 8-m antenna, and the Inmarsat I-4 communications satellites, set to begin

\footnotetext{
${ }^{1}$ U.S. Government work not protected by U.S. copyright.

${ }^{2}$ IEEEAC paper \#1278.
} (7) 7

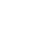
3 
launching in 2003 with 9-m reflectors, have also employed mesh technology.

Other candidate materials for lightweight space antennas include thin metallized membranes, which the NASA Langley Research Center (LaRC) has been developing. Antennas made from these materials can be packaged in small volumes for launch into space and then inflated or tensioned on inflatable, rigidizable structures, depending on the antenna geometries. Inflatable antennas can be stowed in a variety of configurations, are lighter than mesh antennas, and retain their shapes better than mesh once inflated. The inflatable reflector concept was demonstrated by the Inflatable Antenna Experiment (IAE) in 1996 [1]; other configurations for large space antennas using metallized membrane materials have been investigated by Bailey and Campbell [2].

This paper describes work funded by the Gossamer program, in which novel, metallized polymers were synthesized and tested for their reflective and emissive properties at L-band. Because the desired signal for spaceborne radiometric applications consists of thermal noise, the emissivity of the measurement system itself must be very small in order not to overwhelm the quantity being measured. On orbit, a reflector antenna experiences large physical temperature variations, which, multiplied by its emissivity, add to the instrument $\Delta \mathrm{T}$ (radiometric temperature) error. Science requirements that demand extreme accuracy and resolution of the thermal noise allow very small budgets for the $\Delta \mathrm{T}$ of the radiometer; this in turn mandates the use of a reflector antenna having low emissivity. For a representative soil moisture mission using a reflector antenna on low earth orbit, for example, the emissivity requirement for the reflector has been stated as less than 0.003 [3].

\section{Background}

Lightweight Antenna Material Investigations at LaRCNASA LaRC began characterizing the emissivities of materials used for large, lightweight spaceborne antennas in the early 1980's. At that time LaRC and the U.S. Naval Research Laboratory collaborated to characterize metal mesh materials for use in the Low-Frequency Microwave Radiometer (LFMR), which was proposed for the Navy Remote Ocean Sensing System (NROSS) mission (later cancelled) [4]. In the 1990's, LaRC continued and expanded this work by undertaking a measurement program to evaluate the suitability of metallized thin membrane materials for space-based earth remote sensing applications in support of the IAE [1]. In that study, various metal coatings were applied to a thin membrane substrate to study the effects of metal thickness, coating technique, and metal type on the emissivities of the samples. More recently, a tensioned, metallized membrane waveguide array antenna has been developed for which the material emissivity is a very important factor. In addition, new materials such as the ones described in this paper are being developed and characterized to determine their suitability for earth remote sensing antenna applications.

Previous Chemical Techniques-Conventional techniques for the production of metallized polymers have been multistep processes. The films resulting from these processes have exhibited limited adhesion of the applied metal surface layer to the polymer substrate and have been difficult to accomplish over very large surface areas. In contrast, the metallized polymer film/coating process developed at NASA LaRC involves a single-stage, self-metallizing protocol. Films resulting from this process exhibit unfailing mechanical adhesion of metal to polymer because of mechanical interlocking at the polymer/metal interface.

The metallized films are produced from a homogeneous polymer solution containing both a soluble positive-valent metal complex and the desired polymer resin. During thermal curing of the polymer, in situ metal ion reduction also occurs, resulting in a conductive and/or reflective metallic surface layer with additional remaining nanometersized particulates embedded in the bulk of the film. Polymer films containing a variety of metals including silver, gold, palladium, and platinum have been prepared with varying levels of specular reflectivity and surface resistivity. This paper investigates silver, gold, and palladium one-step, self-metallizing films for reflective and emissive properties in the L-band of the spectrum.

In addition to large-scale radio frequency antennas, other potential space applications for metallic films include the following: large-area, lightweight inflatable optics and adaptive optical mirrors [5], [6], solar dynamic power generation [7], [8], gamma ray imaging telescope systems [9], spacecraft charging control, solar reflectors and concentrators [10], radiation shielding, solar sails, sunshields [1], and thermal control coatings. Commercial applications include the following: terrestrial concentration of solar energy to generate electrical power [11]-[13], bactericidal coating/anti-microbial packaging [14], microelectronic contacts [15], and patterned, conductive surfaces on a flexible dielectric base [16].

Previous Measurement Techniques-As explained above, knowledge of the emissivity of reflector materials is crucial to radiometric sensor design. Because the metal component of an experimental, thin, metallized membrane is less than a skin depth and because the molecular construction is different from that of the bulk metal, the electrical properties of a thin membrane are different from those of the bulk metal and must be measured. The techniques that have been developed at LaRC for this purpose use two approaches to the measurement of emissivity. The first approach is to measure the emissivity directly using a radiometer-based system. The second is to use a vector network analyzer (VNA) to measure the material's reflection and transmission coefficients, from which the emissivity can be calculated.

The measurement systems developed in the early 1980's to study emissivities of metallic mesh materials for the LFMR 
were radiometer-based and provided a direct measurement of the emission from the sample. One of the techniques, the "Sky Bucket", was an open system that measured the radiation from the sample against a cold sky background. The drawbacks to this system were the inability to control the physical temperature of the sample and the correction needed for diffraction from the sample fixture.

A closed system was also developed for the LFMR study. This system used a rectangular horn to measure the change in received power as the physical temperature of the sample, which was suspended over a cryoload, was varied. This technique was used again in the metallized thin film study for the IAE experiment in the 1990's. The system suffered from dependence on accurate knowledge of the physical temperature of the sample, as well as variations in the reflection of the cryoload as the nitrogen evaporated.

Due to the lack of repeatability experienced using the closed system, and due to the disagreement of the results obtained by this system with the results of the VNA-based techniques described below, a new radiometric measurement approach was developed in 2001. The Materials Emissivity Measurement System (MEMS) corrected several errors that had been present in the earlier systems and greatly improved accuracy and repeatability for direct emissivity measurement for thin, reflective samples [3]. However, the MEMS required operation over several hours at nighttime with a clear sky, making it somewhat inconvenient to perform emissivity measurements using this system.

Two VNA techniques were developed for the IAE materials study and were based on indirect evaluation of the emissivity using reflection and/or transmission coefficients and the conservation of energy. One, a free-space measurement system, used focused C-band antennas on either side of the sample to measure the transmission coefficient. Since the reflection coefficient was very difficult to measure accurately for highly reflective samples, it was calculated from the transmission coefficient using the fact that the thickness of the sample was much less than a wavelength at the frequencies of interest. Problems with this method included the large working area and large sample size required to perform the measurements at lower frequencies.

The second VNA-based measurement system was based on WR-650 L-band waveguide measurements of a sample mounted on a thin waveguide flange. Repeatability problems occurred with this setup due to inconsistent sample mounting and movement of measurement fixtures during calibration and measurement. Both of the VNA systems were described in detail by Cravey, Blume, et al. [17], who also gave the results of the materials study using both the VNA-based techniques and the radiometric technique described above.

Due to the various drawbacks of each of the measurement systems described above, a more accurate, repeatable, quick, and convenient technique was desired for measuring thin, highly reflective materials. This led to the development of the measurement technique described in this paper, which uses elements of the earlier VNA-based techniques and gives results of the same or better quality compared to the MEMS, without the inconvenience associated with that technique.

\section{EXPERIMENTAL METHOD}

The following section is divided into the methods for chemically synthesizing the metallized polymers, for characterizing their physical properties and appearance, and for measuring their electromagnetic properties.

\section{Metallized Polymer Fabrication}

Materials-Table 1 lists the aromatic dianhydrides and diamines used in the preparation of polyimides for this work. The dianhydrides, 3,3',4,4'-benzophenonetetracarboxylic dianhydride (BTDA) and 2,2-bis(3,4dicarboxyphenyl)hexafluoropropane dianhydride (6FDA), were obtained from Allco Chemical Corporation and Hoechst Aktiengsellschaft, respectively. The diamines, 4,4'-oxydianiline (4,4'-ODA) and 2,2-bis[4-(4aminophenoxy)phenyl]hexafluoropropane (4-BDAF), were obtained from Kennedy \& Klim, Inc. and the Ethyl Corporation. The solvent, N,N-dimethylacetamide (DMAc), was obtained from Aldrich Chemical Co. Melting points and monomer purification were performed prior to use to insure high molecular weights of the polyamic resins and polyimide films.

The metal dopants used were hydrogen tetrachloroaurate (III) trihydrate (auric acid), bis(dimethylsulfide)dichloropalladium (II) complex $\left(\mathrm{Pd}\left[\mathrm{S}\left(\mathrm{CH}_{3}\right)_{2}\right]_{2} \mathrm{Cl}_{2}\right)$, and silver 1,1,1-trifluoro-2,4-pentadionate (AgTFA). The auric acid was added as obtained from Aldrich Chemical Co. The $\operatorname{Pd}\left[\mathrm{S}\left(\mathrm{CH}_{3}\right)_{2}\right] \mathrm{Cl}_{2}$ was prepared by dissolving palladium chloride $\left(\mathrm{PdCl}_{2}\right)$ in an excess of dimethyl sulfide $\mathrm{S}\left(\mathrm{CH}_{3}\right)_{2}$ and evaporating the product to dryness. The product was then recrystallized from ethanol and dried under vacuum at $60{ }^{\circ} \mathrm{C}$ for 2 to 3 hours. AgTFA was synthesized by dissolving silver (I) acetate into an excess of 1,1,1-trifluoro2,4-pentadionate (TFAH) using a method analogous to the one reported by Wenzel and Sievers [18]. A list of the metal dopants and polyimide resins used in this study is presented in Table 1.

Preparation of Polyimide Films-The polymers used in this study were BTDA/4,4'-ODA, BTDA/4-BDAF, and 6FDA/4-BDAF (LaRC-CP1 ${ }^{\mathrm{TM}}$ ). The reaction route for the preparation of a polyamic acid, BTDA/4,4'-ODA, and a polyimide film is presented in Figure 1. The BTDA/4,4'ODA polyamic acid resin was prepared from equimolar amounts of BTDA and 4,4'-ODA in solution containing $15 \%$ solids (w/w) in DMAc. The reaction consisted of first dissolving 4,4'-ODA in DMAc in a flask flushed with dry nitrogen and then adding the BTDA and stirring at room temperature for a minimum of 5 hours. The polyamic resins 
for BTDA/4-BDAF and LaRC-CP1 ${ }^{\mathrm{TM}}$ were prepared by reactions analogous to the one described above.

Metal additives were incorporated into polyamic acid resins and stirred until completely dissolved. All additives had been prescreened for solubility in the polymer solutions. The concentration of the metal additives was between 5 and $20.5 \%$ by weight. The metal-doped polyamic acid resins were cast as films onto soda lime glass plates using a doctor blade that was set to obtain a cured film thickness of $2.45 \times$ $10^{-3} \mathrm{~cm}$. Films were imidized by heating in a forced air oven for $1 \mathrm{hr}$ each at 100,200 , and $300{ }^{\circ} \mathrm{C}$ for the gold and palladium films. The silver films were cured by heating for $1 \mathrm{hr}$ at $135^{\circ} \mathrm{C}$, ramping to $300{ }^{\circ} \mathrm{C}$ over a 4-hour period, and holding at $300{ }^{\circ} \mathrm{C}$ for 5 hours. Cured films were removed from the glass plates by soaking in water.

Table 1. Metal Additives and Polyamic Acid Resins

\begin{tabular}{|c|c|c|c|}
\hline $\begin{array}{c}\text { Metal/ } \\
\text { Additive }\end{array}$ & Chemical Formula of Additive & \% Metal in Film & $\begin{array}{c}\text { Polyamic } \\
\text { Acid Resin }\end{array}$ \\
\hline \hline $\begin{array}{c}\text { Palladium }(\mathrm{Pd}) \\
\mathrm{Pd}\left(\mathrm{SMe}_{2}\right)_{2} \mathrm{Cl}_{2}\end{array}$ & $\mathrm{Pd}\left[\mathrm{S}\left(\mathrm{CH}_{3}\right)_{2}\right] \mathrm{Cl}_{2}$ & 5.0 & BTDA/ODA \\
\hline $\begin{array}{c}\text { Silver }(\mathrm{Ag}) \\
\mathrm{Ag}(\mathrm{I}) \mathrm{TFA}\end{array}$ & $\mathrm{Ag}\left(\mathrm{CF}_{3} \mathrm{COCH}_{2} \mathrm{COCH}_{3}\right)$ & 13.0 & BTDA/ODA \\
\hline $\begin{array}{c}\text { Gold (Au) } \\
\text { Auric acid }\end{array}$ & $\mathrm{HCl}_{4} \mathrm{Au} \bullet 3 \mathrm{H}_{2} \mathrm{O}$ & 20.5 & BTDA/4-BDAF \\
\hline $\begin{array}{c}\text { Gold (Au) } \\
\text { Auric acid }\end{array}$ & $\mathrm{HCl}_{4} \mathrm{Au} \bullet 3 \mathrm{H}_{2} \mathrm{O}$ & 20.5 & LaRC-CP1 \\
\hline
\end{tabular}

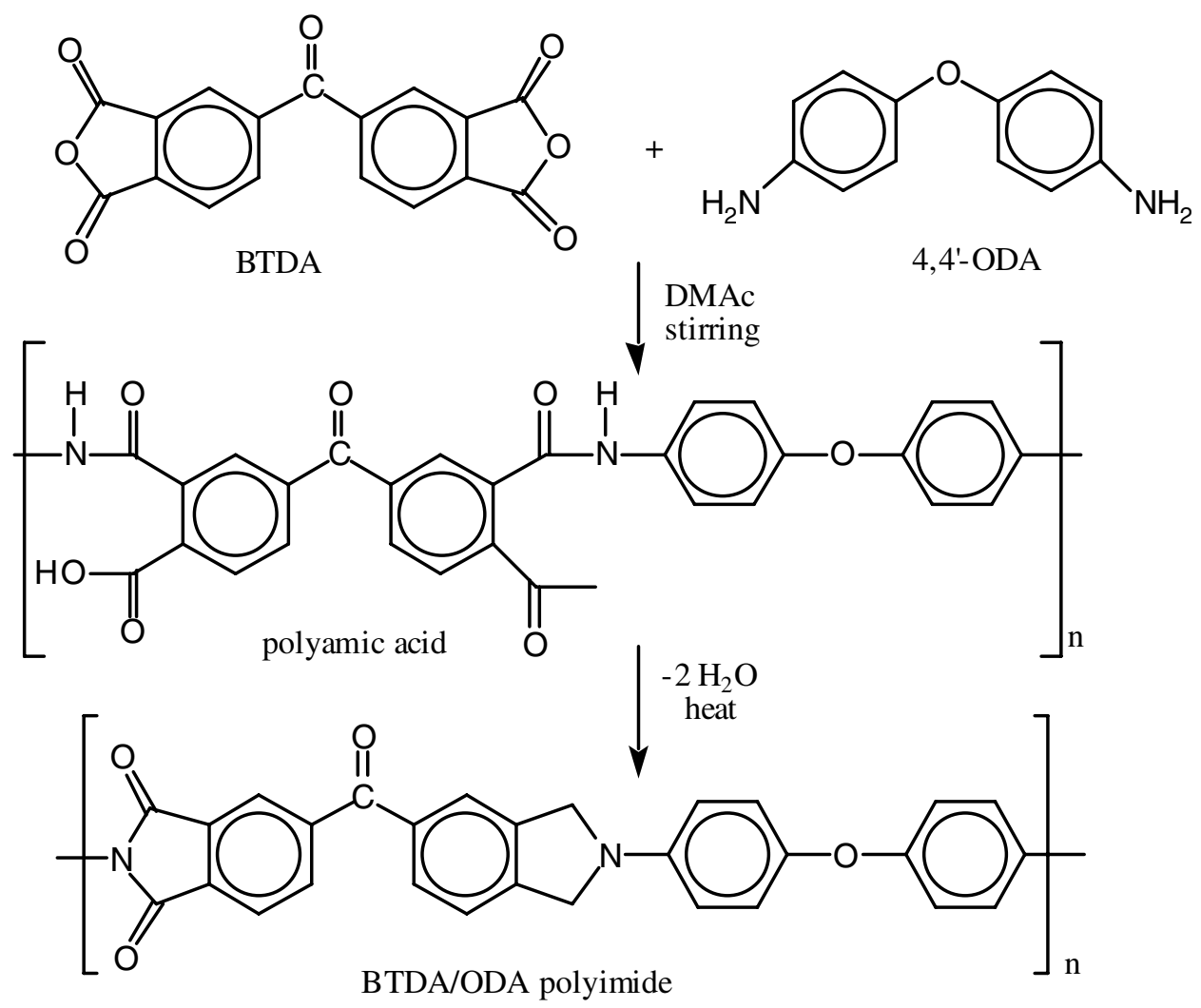

Figure 1 - Synthesis of BTDA/ODA polyimide. 


\section{Physical Characterization}

Monomer and metal additive melting points (onset) were determined by differential scanning colorimetry (DSC) at a heating rate of $20{ }^{\circ} \mathrm{C} / \mathrm{min}$ on a TA Instruments DSC 2920 Modulated DSC. Inherent viscosities of the polyamic acid resins were determined prior to use, as an indicator of polymer molecular weight. The inherent viscosities of the polyamic acid resins were obtained at a concentration of $0.5 \%(\mathrm{w} / \mathrm{w})$ in DMAc at $35{ }^{\circ} \mathrm{C}$. A minimum inherent viscosity of $1.0 \mathrm{dL} / \mathrm{g}$ at $35^{\circ} \mathrm{C}$ was required for all polyamic acid resins to be considered for use in this study. Polymer melting points and polymer decomposition points were determined on a TA Instruments thermomechanical analyzer (TMA), Model 2940, and thermogravimetric analyzer (TGA), Model 2950, respectively.

Transmission electron microscopy (TEM) was performed at Auburn University's Research Instrumentation Facility, Auburn, AL on a Philips CM-20T transmission electron microscope operating at $200 \mathrm{keV}$. Scanning electron microscopy (SEM) was performed in the Microelectronics and Sensor Development Section at NASA Langley Research Center on an Amray scanning electron microscope, Model 1700. The total film thicknesses were determined using a TMI Precision Micrometer, and the thicknesses of the metal layers alone were estimated from the TEM's.

\section{Electromagnetic Characterization}

An HP 8510 Vector Network Analyzer was used to measure the scattering parameters of the metallized membranes. These parameters included S11, the forward reflection coefficient; S21, the forward transmission coefficient; S22, the reverse reflection coefficient; and S12, the reverse transmission coefficient. From these quantities the power coefficients reflectivity, transmissivity, and emissivity ( $R$, $\mathrm{T}$, and E) were calculated.

Sample Preparation-The thin film samples were cut and adhered to titanium frames using double-sided tape of thickness $4.1 \mathrm{mil}$. Enough bare metal was left around the edges of the frames to allow good conductivity from one side of the L-band waveguide through the frame to the other side of the waveguide. Figure 2 shows a photograph of a prepared gold film sample. The frame was then bolted into the L-band test fixture for the two-port measurement; once in place, the film completely filled the waveguide opening.

L-Band Test Fixture-A test fixture positioner was custommade to position the waveguide apparatus, allowing the waveguide to be opened and closed many times in a highly repeatable manner. The test fixture and positioner are shown in Figure 3. The port 1 side of the waveguide, along with its attached cable, was fixed in place. The port 2 side of the waveguide was allowed, by means of an X-Y slide, to open and accommodate a sample and then close in precisely the same place where it had been during the calibration sequence. The cable attached to the movable side of the waveguide was disturbed as little as possible, as it was noted that cable movements could produce measurable differences in the results. The test fixture positioner greatly facilitated the repeatability of results over the period of days when a particular sample was measured.

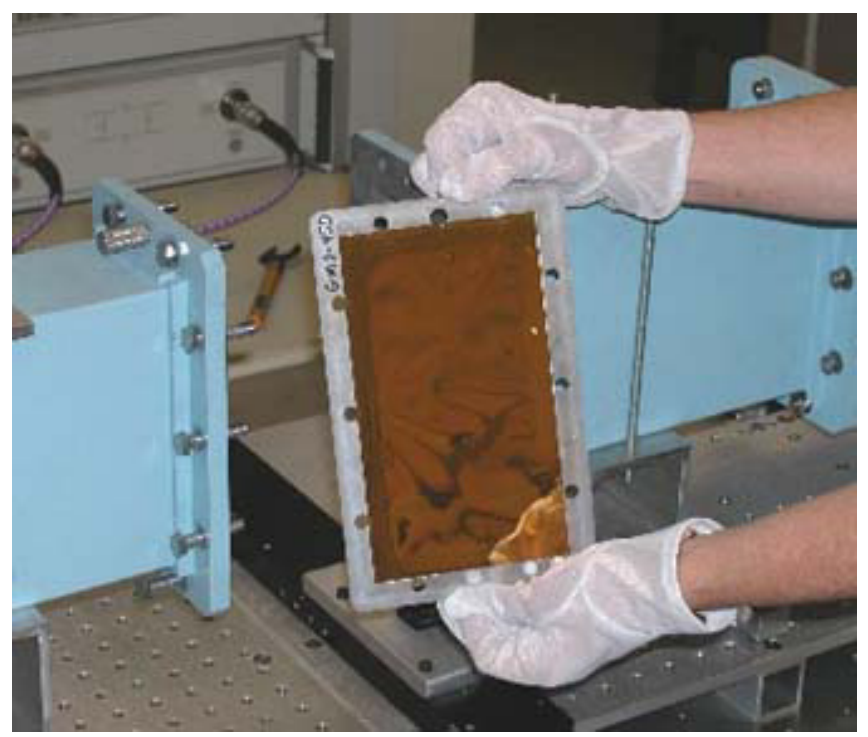

Figure 2 - Gold film mounted onto frame.

Calibration-A Thru-Reflect-Line (TRL) 2-Port VNA calibration was performed at the beginning of each day's tests to correct for systematic measurement errors. This method is particularly good for very highly reflective samples, which it was hoped that the metallized polymers would be. During the calibration sequence, the empty waveguide test fixture served as the "thru" device. The "reflect" device was a flat aluminum plate providing a complete short and defining the reference plane. The "line" device was a short waveguide section of known length. Also measured were fixed loads, which acted as absorbers, to test the isolation of the two ports. The VNA made corrections to all subsequently measured data based on the measured and known values for the calibration devices.

The Full 2-Port calibration method, another method tried previously, had allowed more uncertainty due to residual source match error when used in conjunction with highly reflective samples. In comparison, the TRL method characterized the source mismatch error more accurately, substantially reducing the residual source match error after error correcting had been applied. The result was much smoother, less biased, corrected S11 and S22 versus frequency curves. Even with error correcting applied, it was observed that often the forward and reverse measurements would be slightly biased $(\sim 0.001 \mathrm{db})$ in opposite directions; therefore it was useful to average forward and reverse measurements taken together. This was allowable because, at L-band, the metallized films exhibited the same electromagnetic properties on both sides. 


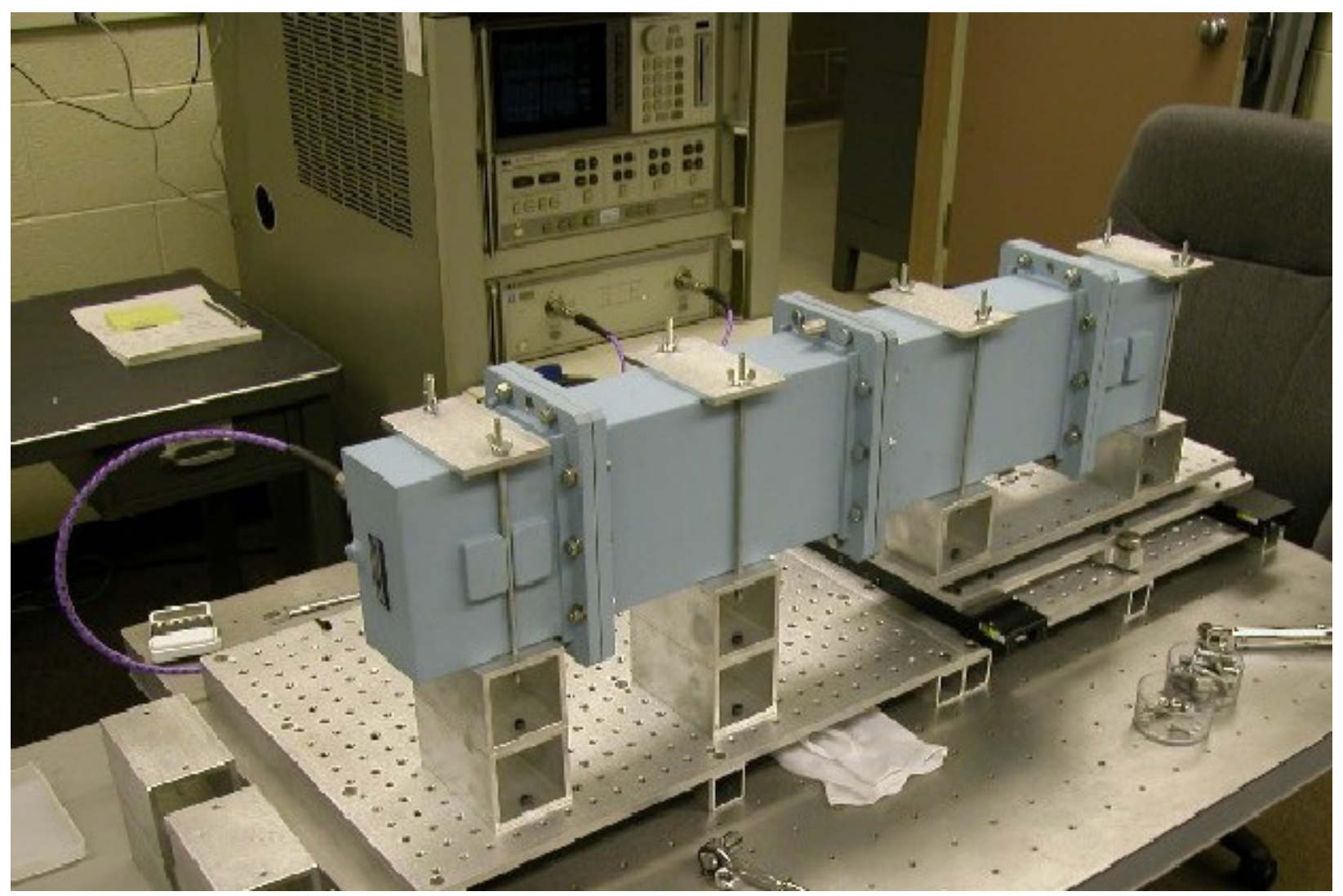

Figure 3 - L-band waveguide test fixture with positioner and HP 8510 Vector Network Analyzer.

Sample Measurements-Data were recorded at each of 401 frequencies from 1.12 to $1.7 \mathrm{GHz}$ using 128-point averaging, while the source power was held constant at 10 $\mathrm{dBm}$. The S-parameters S11, S21, S22, and S12 were measured. Generally, each sample was measured three times on each of two or three days.

Calculations-The power coefficients were calculated in the forward direction as

$$
\begin{gathered}
R=|S 11|^{2} \\
T=|S 21|^{2} \\
E=1-|S 11|^{2}-|S 21|^{2}
\end{gathered}
$$

The power coefficients were calculated in the reverse direction as

$$
\begin{gathered}
R=|S 22|^{2} \\
T=|S 12|^{2} \\
E=1-|S 22|^{2}-|S 12|^{2}
\end{gathered}
$$

In order to report mid-band values for each sample, the results were curve fitted and calculated at $1.414 \mathrm{GHz}$.
For very highly reflective ${ }^{3}$, slightly transmissive samples, the measured S21 (S12) was much less noisy than the measured S11 (S22); in these cases S11 (S22) was calculated from the complex measured S21 (S12). The calculation method has been derived by Cravey, Blume, et al. [17] using transmission line theory. Because the VNA could measure transmission coefficients as small as $-60 \mathrm{~dB}$, very little transmission was necessary for this method, which was performed as follows.

Defining the test article (film sample with frame) to have a zero-length shunt admittance of $\mathrm{Y}$ at the measurement plane and defining the transmission line (waveguide) admittance to be $\mathrm{Y}_{0}$, one may show that, for the forward direction:

$$
S 11=\frac{-Y}{Y+2 Y_{0}}
$$

and

$$
S 21=\frac{2 Y_{0}}{Y+2 Y_{0}}
$$

Rearranging (8) to solve for $\mathrm{Y}$,

$$
Y=\frac{2 Y_{0}\left(1-S_{21}\right)}{S_{21}}
$$

\footnotetext{
${ }^{3}$ In the group of samples described by this report, $\mathrm{R} \geq 90 \%$ for highly reflective materials.
} 
where

$$
Y_{0}=\frac{\sqrt{1-\left(\frac{f_{\text {cutoff }}}{f}\right)^{2}}}{\eta_{\text {air }}}
$$

Also, $\mathrm{f}_{\text {cutoff }}=908 \mathrm{MHz}$, the intrinsic impedance $\eta_{\text {air }}=377 \Omega$, and $\mathrm{S} 21$ is the measured value. Substituting $\mathrm{Y}$ and $\mathrm{Y}_{0}$ back into (7), one may solve for S11. S22, the reverse direction reflection coefficient, is calculated in an analogous manner.

S11 and S22 thus calculated provided much smoother reflectivity versus frequency and emissivity versus frequency curves than the reflection coefficients directly calculated from the measured S11 and S22.

\section{RESULTS}

\section{Physical Properties}

Seven $12^{\prime \prime} \times 12^{\prime \prime}$ films were prepared for this study: two silver and two palladium-doped films in BTDA/4,4'ODA, two gold-doped films in BTDA/4,4-BDAF and one golddoped LaRC-CP1 $1^{\mathrm{TM}}$ film. All films were fingernail creasable, flexible, and visibly reflective with the exception of one silver film that was hazy in appearance. The glass transition $(\mathrm{Tg})$ temperatures of the silver films were similar to neat BTDA/4,4'-ODA films (Table 2); however, the polymer decomposition temperatures (TGA) at $10 \%$ weight loss were significantly depressed, showing the effect of the metal on the base polymer. The palladium-doped films had significant $\mathrm{Tg}$ and TGA depression, typical of palladium systems due to the highly catalytic nature of palladium. For the gold-doped BTDA/4-BDAF films, the Tg was slightly higher, while the TGA at $10 \%$ weight loss was also depressed. Finally, for the gold-doped LaRC-CP1 ${ }^{\mathrm{TM}}$ films, both the Tg and TGA were slightly depressed.

Micrometer measurements found the total film average thicknesses to lie between 13.9 and $32.5 \mu \mathrm{m}$. Of these total thicknesses, the metal layers comprised between 0.07 and $0.53 \%$. The total film weights varied from 0.031 to 0.044 $\mathrm{kg} / \mathrm{m}^{2}$. These results are shown in the summary Table 2 .

\section{TEM's, SEM's, and Electromagnetic Properties}

For four films including the mirror-like AgTFA:BTDA/ODA film, the hazy AgTFA:BTDA/ODA film, one Pd:BTDA/ODA film, and one Au:BTDA/4-BDAF film, example TEM, SEM, S11, S21, reflectivity, and emissivity results have been grouped so that figures for the same metal appear on the same page following. A TEM and an SEM of the Au:CP1 film are also shown in Figure 16. Transmission and scanning electron microscopy of the films (Figures 4, 7, 10, 13, and 16) show the cross section and topography of the metallic layer; in addition, the TEM's show the distribution of the nanosized metal particles within the polymer matrix.

Table 2. Physical Properties of Neat and Metallized Polymer Films

\begin{tabular}{|c|c|c|c|c|c|c|c|}
\hline Base Resin & $\%$ Metal & $\begin{array}{l}\text { Final } \\
\text { Film } \\
\text { Thickness } \\
\text { (m) }\end{array}$ & $\begin{array}{c}\text { Metal } \\
\text { Layer } \\
\text { Thickness } \\
\text { (m) }\end{array}$ & $\begin{array}{l}\text { Film } \\
\text { Weight } \\
\left(\mathbf{k g} / \mathrm{m}^{2}\right)\end{array}$ & $\begin{array}{l}\mathrm{Tg} \\
\left({ }^{\circ} \mathbf{C}\right)\end{array}$ & $\begin{array}{c}\text { TGA, } \\
10 \% \\
\text { Wt. } \\
\text { Loss } \\
{ }^{\circ} \mathrm{C} \\
\end{array}$ & $\begin{array}{c}\text { Film } \\
\text { Appearance }\end{array}$ \\
\hline BTDA/ODA & - & $\sim 2.54$ E-5 & - & 0.033 & 280 & 525 & $\begin{array}{l}\text { Dark yellow } \\
\text { Flexible }\end{array}$ \\
\hline BTDA/ODA & $13.0 \% \mathrm{Ag}$ & $\begin{array}{c}2.74 \text { E-5 } \\
2.28-2.79 \text { E-5 }\end{array}$ & $\begin{array}{l}1.88 \mathrm{E}-8 \\
3.25 \mathrm{E}-8\end{array}$ & 0.043 & $\begin{array}{l}271 \\
284\end{array}$ & $\begin{array}{l}369 \\
385\end{array}$ & $\begin{array}{l}\text { Mirror-like or } \\
\text { hazy/white, } \\
\text { flexible }\end{array}$ \\
\hline BTDA/ODA & $5.0 \% \mathrm{Pd}$ & $\begin{array}{l}0.66-2.11 \mathrm{E}-5 \\
1.02-2.29 \mathrm{E}-5\end{array}$ & $\begin{array}{l}3.22 \mathrm{E}-8 \\
4.02 \mathrm{E}-8\end{array}$ & 0.031 & $\begin{array}{l}250 \\
259\end{array}$ & 300 & $\begin{array}{c}\text { Metallic, } \\
\text { flexible }\end{array}$ \\
\hline BTDA/4-BDAF & - & $\sim 2.54 \mathrm{E}-5$ & - & 0.032 & 247 & 510 & $\begin{array}{l}\text { Pale yellow } \\
\text { Flexible }\end{array}$ \\
\hline BTDA/4-BDAF & $20.5 \% \mathrm{Au}$ & $\begin{array}{l}2.72 \text { E-5 } \\
3.28 \text { E-5 }\end{array}$ & $\begin{array}{l}5.09 \mathrm{E}-8 \\
7.19 \mathrm{E}-8\end{array}$ & 0.036 & $\begin{array}{l}250 \\
259\end{array}$ & 492.5 & $\begin{array}{l}\text { Metallic gold, } \\
\text { flexible }\end{array}$ \\
\hline $\begin{array}{c}\text { LaRC-CP1 } \\
\text { 6FDA/4-BDAF }\end{array}$ & - & $2.29 \mathrm{E}-5$ & - & 0.044 & 263 & 510 & $\begin{array}{c}\text { Clear } \\
\text { Flexible }\end{array}$ \\
\hline $\begin{array}{c}\mathrm{CP} 1 \\
6 \mathrm{FDA} / 4-\mathrm{BDAF}\end{array}$ & $20.5 \% \mathrm{Au}$ & $2.26 \mathrm{E}-5$ & $12.05 \mathrm{E}-8$ & 0.036 & 242 & 494 & $\begin{array}{l}\text { Metallic gold, } \\
\text { flexible }\end{array}$ \\
\hline
\end{tabular}




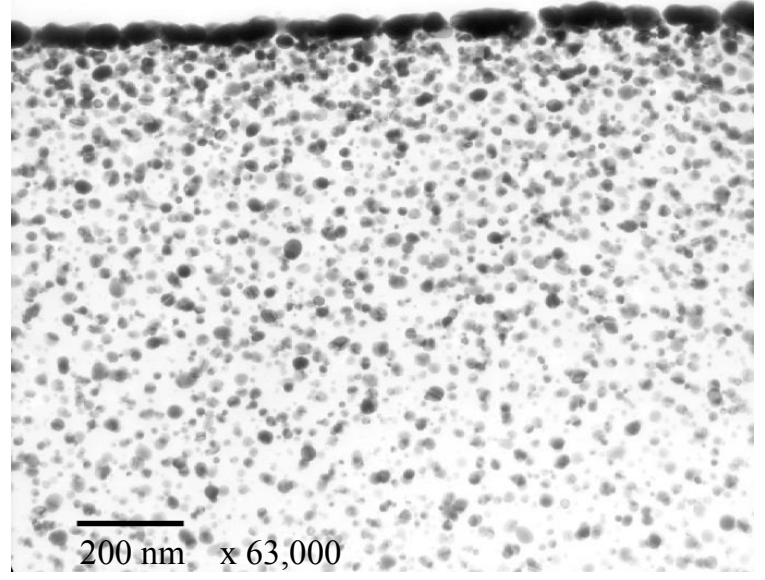

Figure 4a-TEM for 13\% Ag:BTDA/ODA mirror finish. Figure $\mathbf{4 b}$ - SEM for 13\% Ag:BTDA/ODA mirror finish.

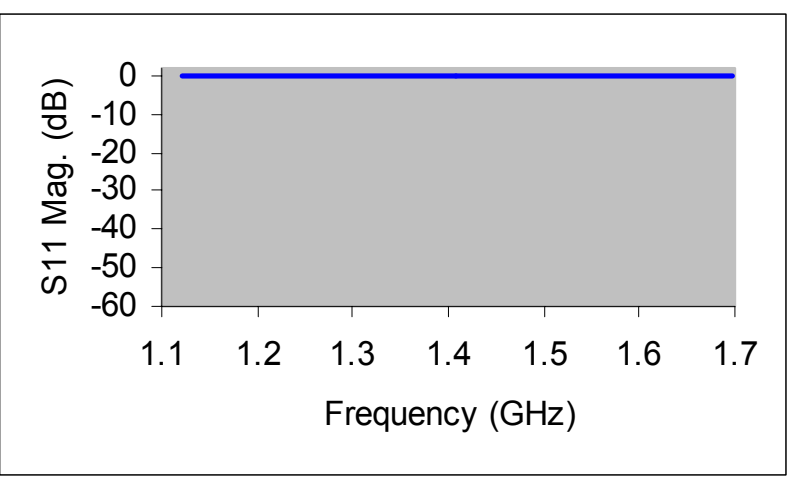

Figure 5a - $|\mathrm{S} 11|$ for 13\% Ag:BTDA/ODA mirror finish.

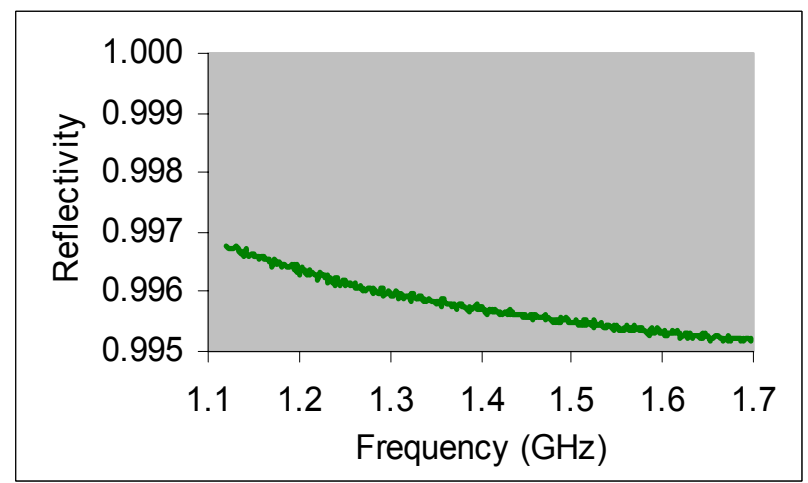

Figure 6a- R for 13\% Ag:BTDA/ODA mirror finish.
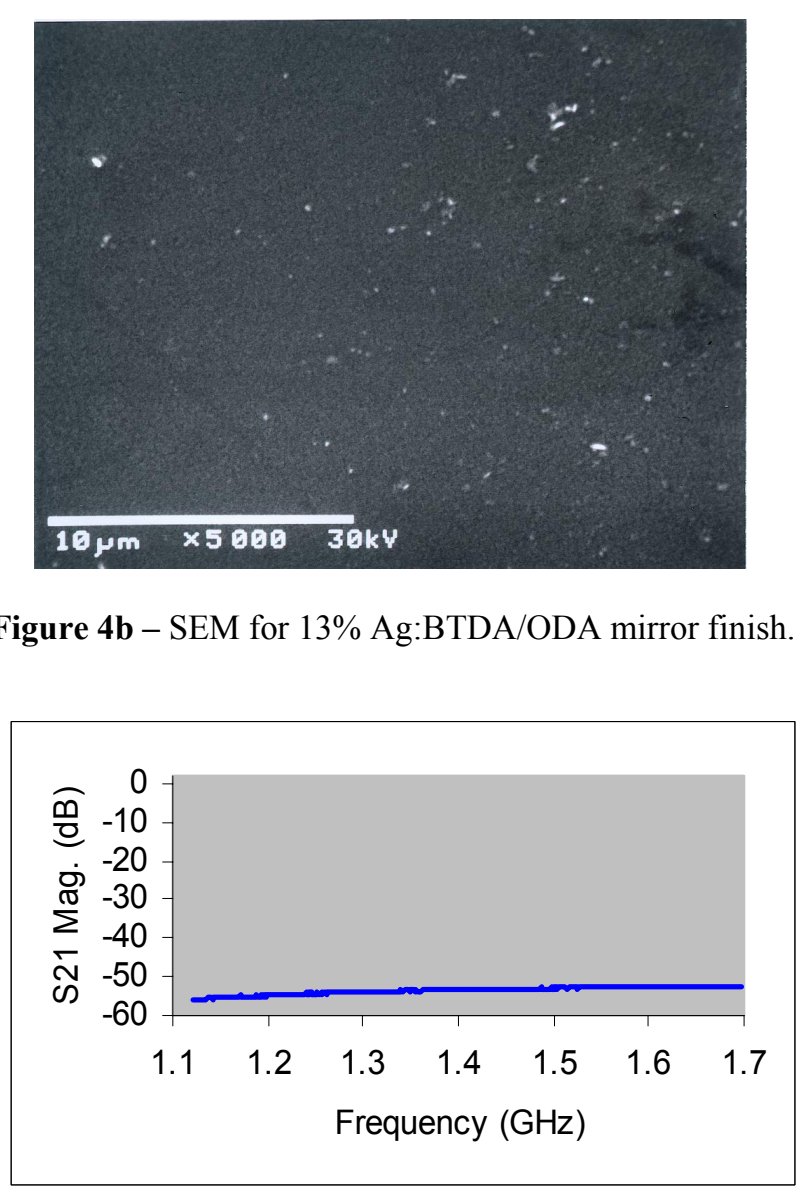

Figure 5b - |S21| for 13\% Ag:BTDA/ODA mirror finish.

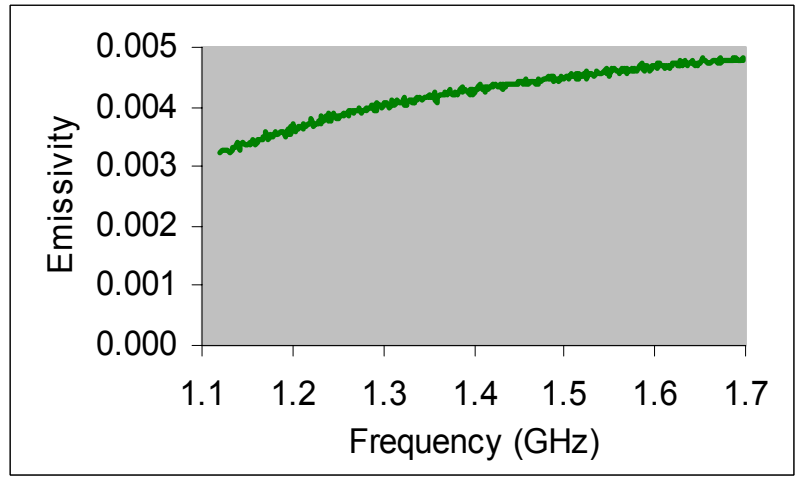

Figure $\mathbf{6 b}-\mathrm{E}$ for $13 \% \mathrm{Ag}$ :BTDA/ODA mirror finish. 
Silver Film, Hazy Finish

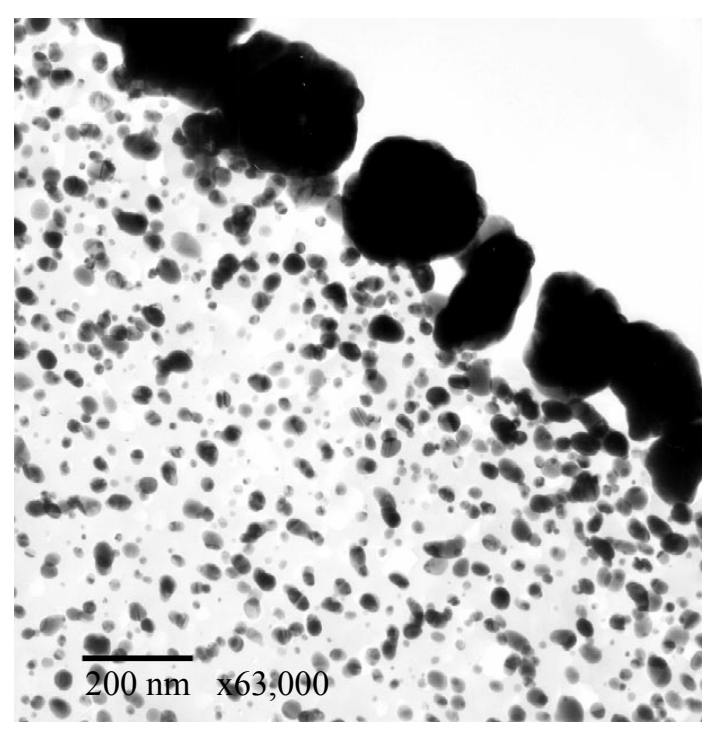

Figure 7a - TEM for 13\% Ag:BTDA/ODA hazy finish.

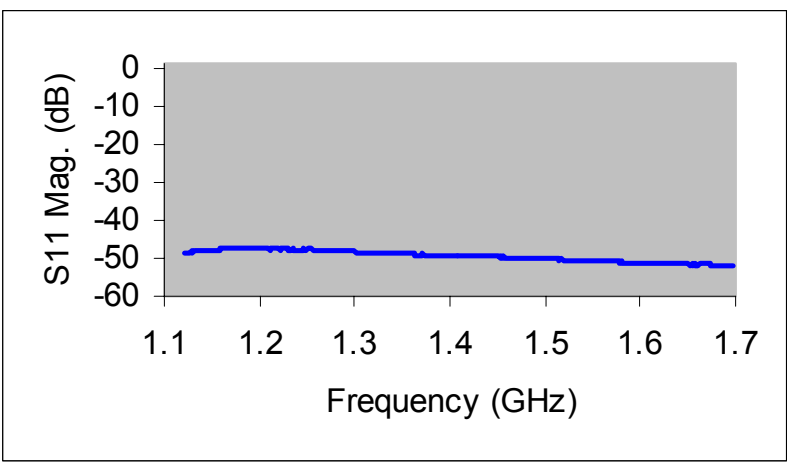

Figure 8a - $|\mathrm{S} 11|$ for 13\% Ag:BTDA/ODA hazy finish.

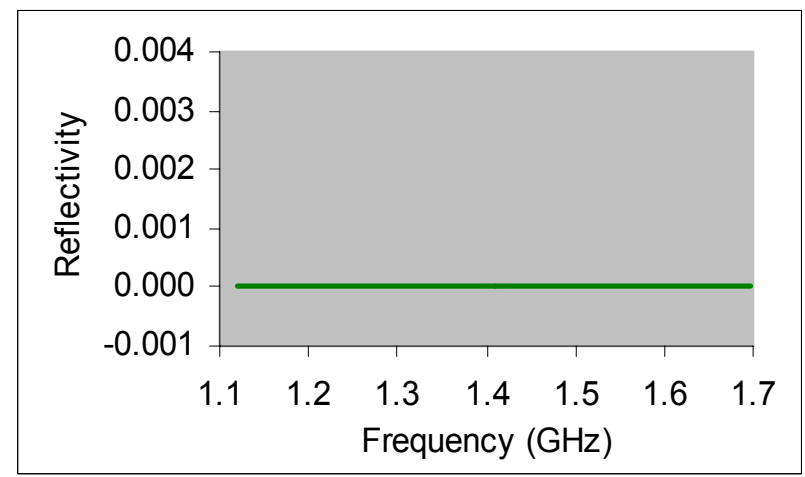

Figure $9 \mathrm{a}-\mathrm{R}$ for $13 \% \mathrm{Ag}$ :BTDA/ODA hazy finish.

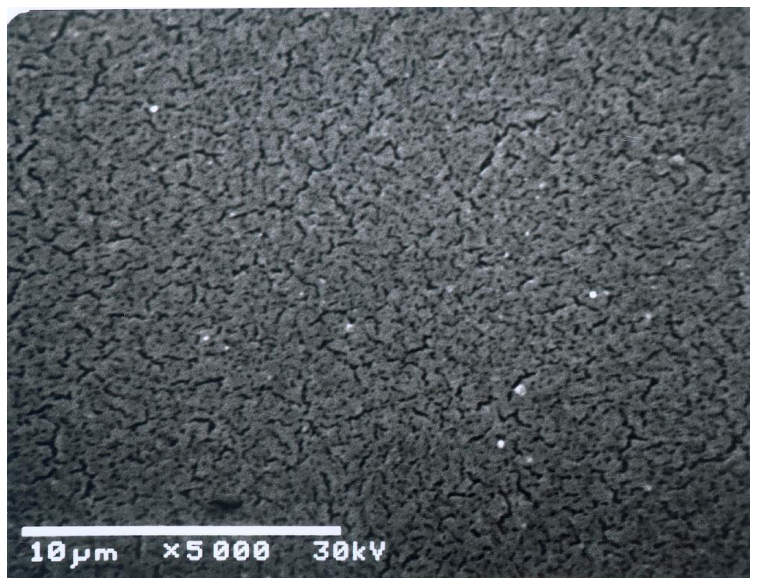

Figure 7b-SEM for 13\% Ag:BTDA/ODA hazy finish.

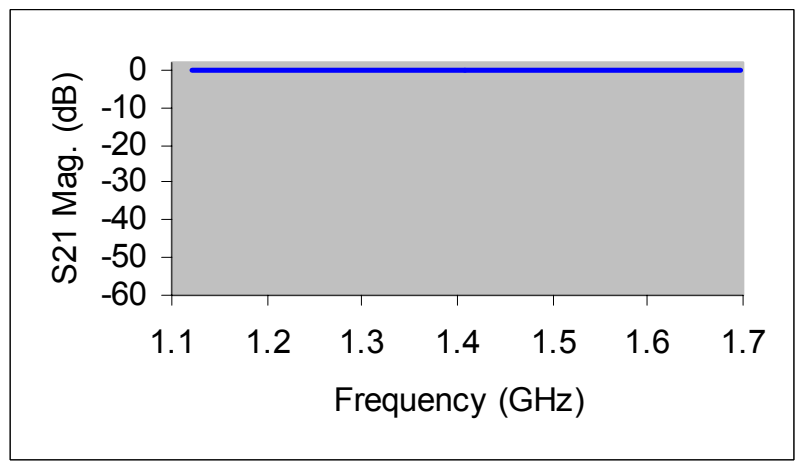

Figure 8b - |S21| for 13\% Ag:BTDA/ODA hazy finish.

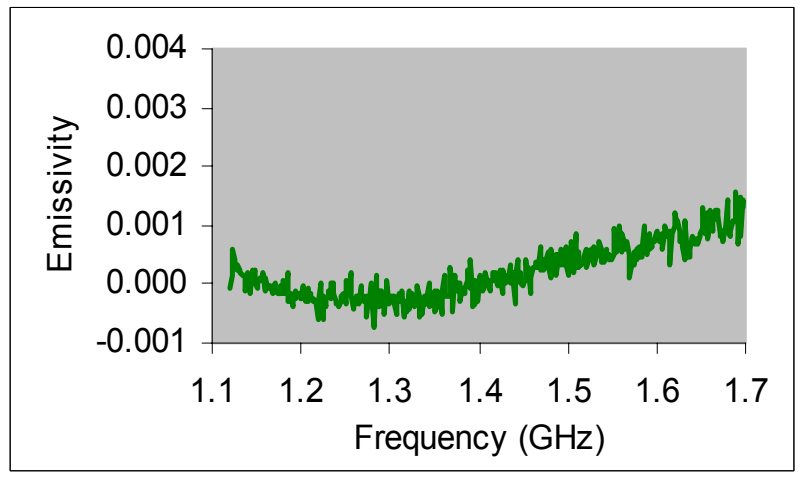

Figure $9 \mathbf{b}-\mathrm{E}$ for $13 \% \mathrm{Ag}$ :BTDA/ODA hazy finish. 
Palladium Film

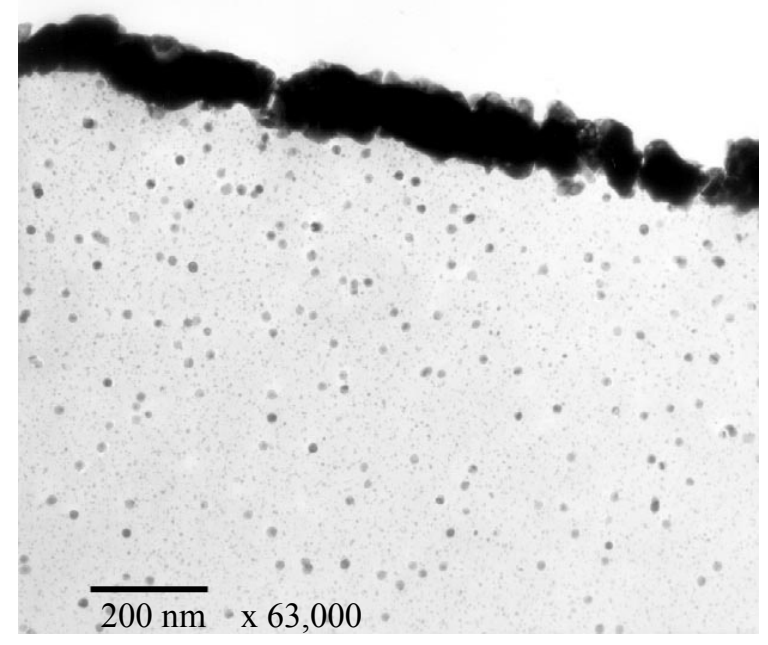

Figure 10a - TEM for 5\% Pd:BTDA/ODA.

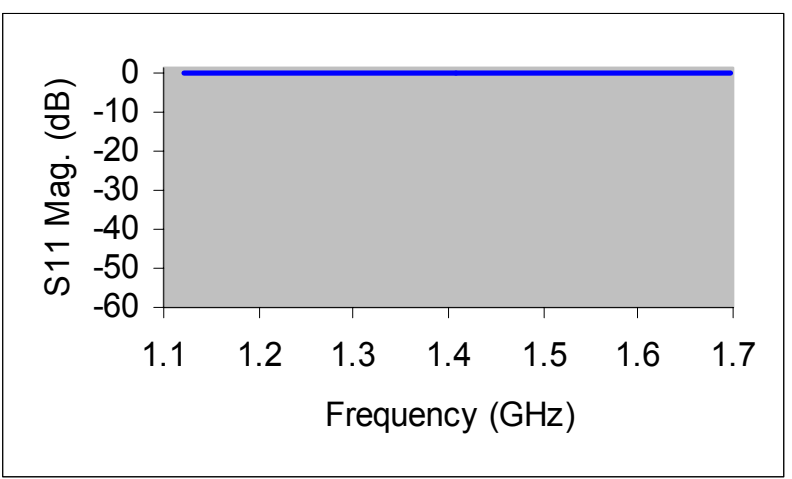

Figure 11a - $|\mathrm{S} 11|$ for 5\% Pd:BTDA/ODA.

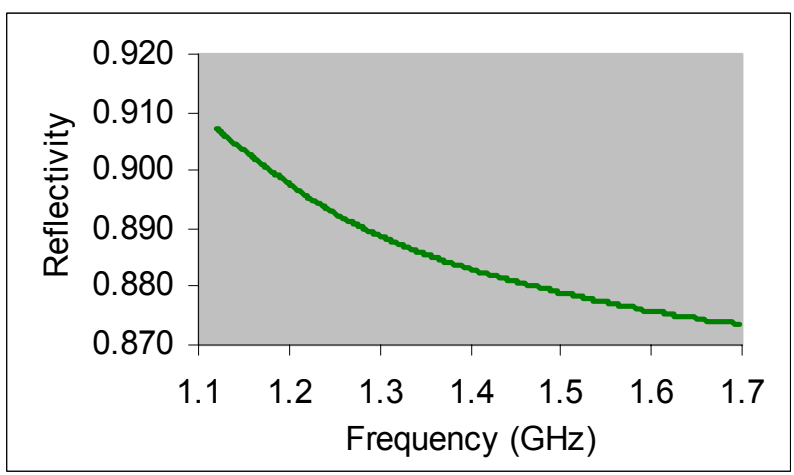

Figure 12a - R for 5\% Pd:BTDA/ODA.

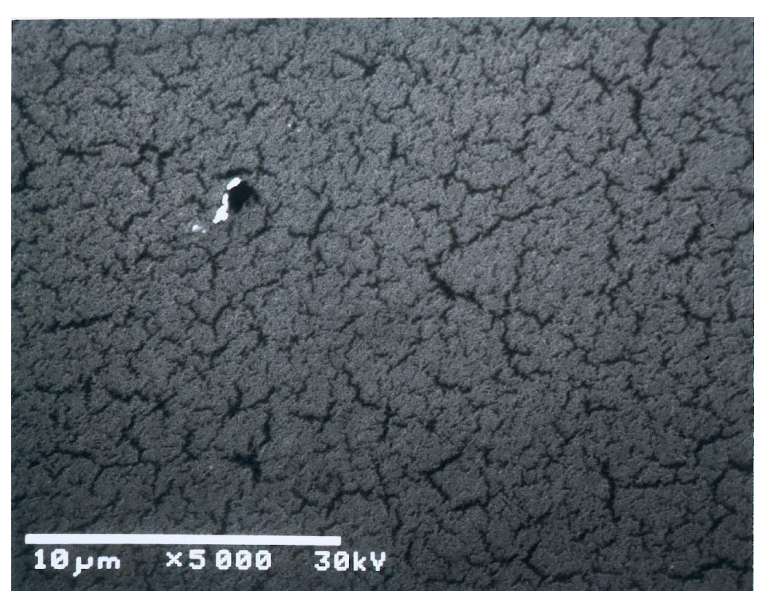

Figure 10b - SEM for 5\% Pd:BTDA/ODA.

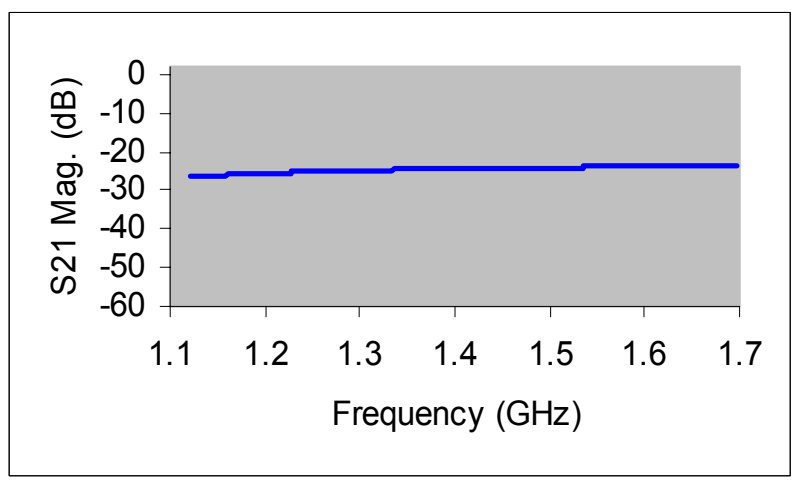

Figure 11b - $|\mathrm{S} 21|$ for $5 \%$ Pd:BTDA/ODA.

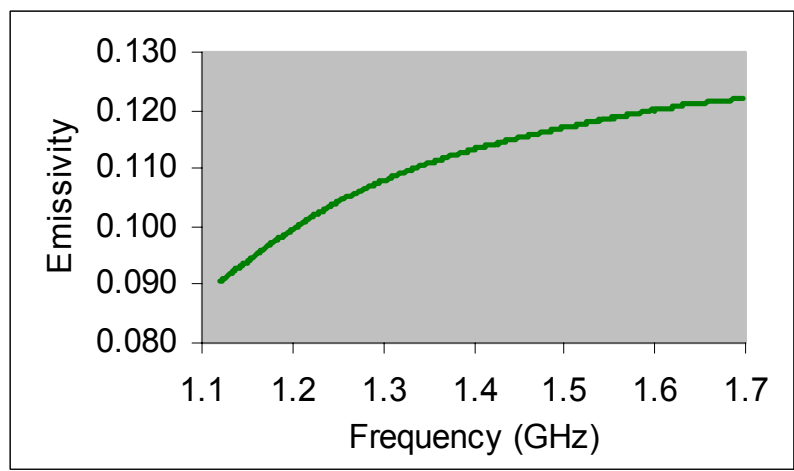

Figure 12b - E for 5\% Pd:BTDA/ODA. 
Gold Film, BTDA/4-BDAF

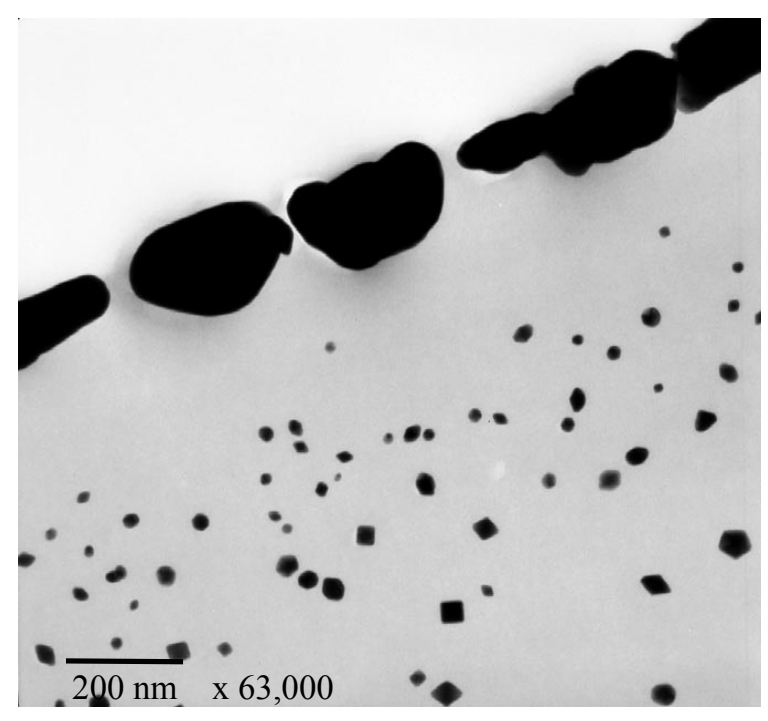

Figure 13a - TEM for $20.5 \%$ Au:BTDA/4-BDAF.

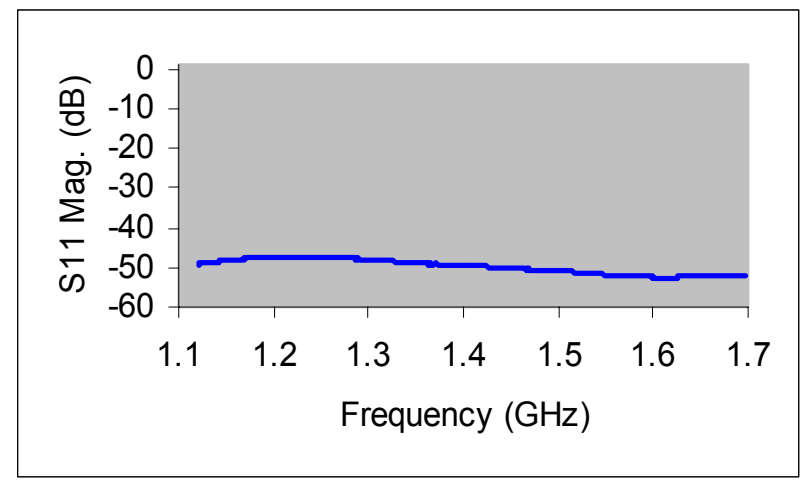

Figure 14a - $|\mathrm{S} 11|$ for $20.5 \% \mathrm{Au}$ BTDA/4-BDAF.

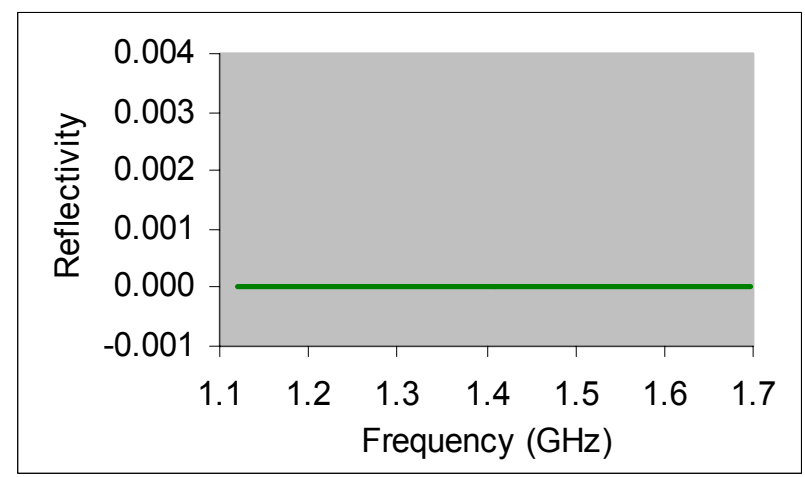

Figure 15a - R for 20.5\% Au:BTDA/4-BDAF.

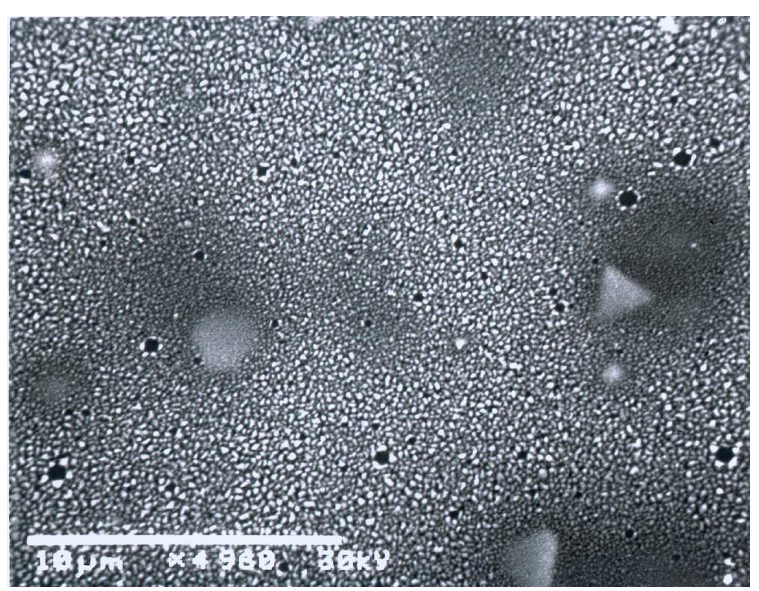

Figure 13b - SEM for $20.5 \%$ Au:BTDA/4-BDAF.

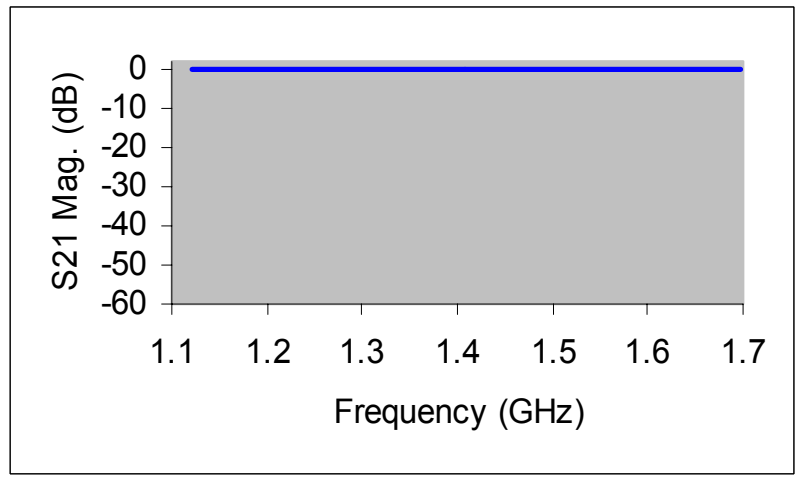

Figure 14b - $|\mathrm{S} 21|$ for $20.5 \% \mathrm{Au}$ BTDA/4-BDAF.

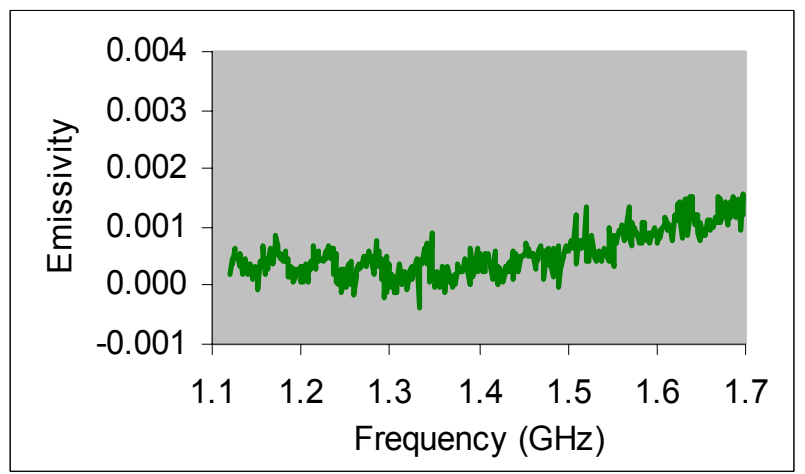

Figure 15b - E for 20.5\% Au:BTDA/4-BDAF. 


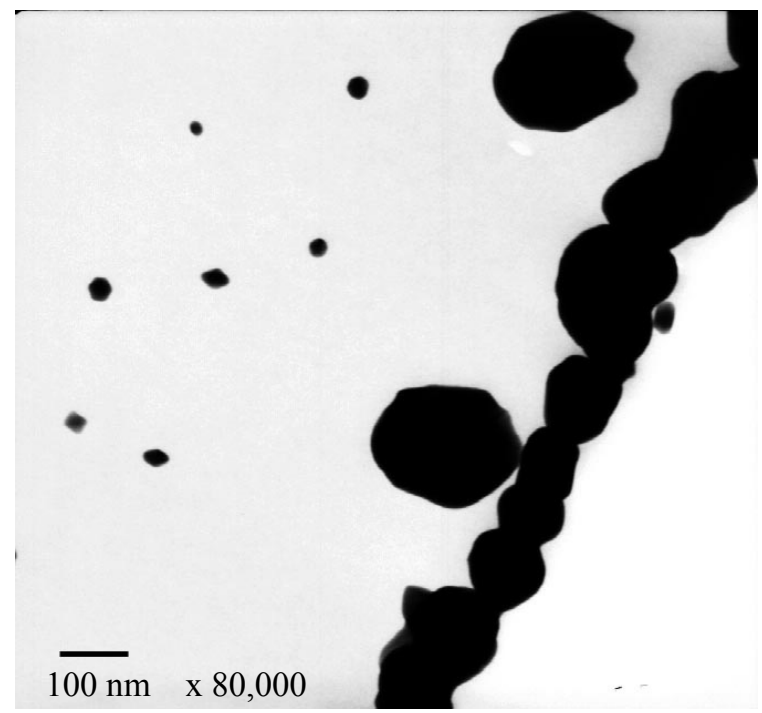

Figure 16a - TEM for 20.5\% Au:CP1 (space durable polyimide).

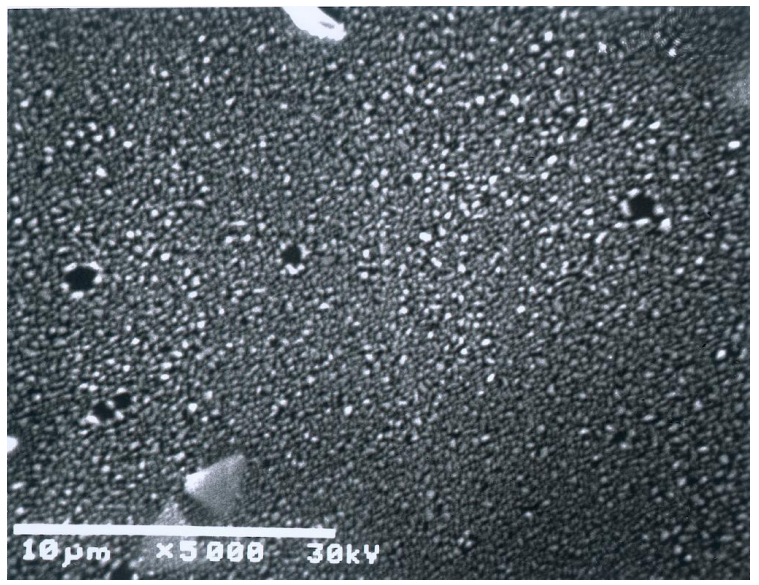

Figure 16b - SEM for 20.5\% Au:CP1 (space durable polyimide).

Table 3. Average Power Coefficients Calculated at $1.414 \mathrm{GHz}$

\begin{tabular}{|c|c|c|c|}
\hline Metallized Polymer & $\begin{array}{c}\text { Reflectivity } \\
\text { at } \mathbf{1 . 4 1 4} \mathbf{~ G H z}\end{array}$ & $\begin{array}{c}\text { Transmissivity } \\
\text { at } \mathbf{1 . 4 1 4} \mathbf{~ G H z}\end{array}$ & $\begin{array}{c}\text { Emissivity } \\
\text { at } \mathbf{1 . 4 1 4} \mathbf{~ G H z}\end{array}$ \\
\hline \hline $\begin{array}{c}13 \% \text { AgTFA:BTDA/ODA } \\
\text { Mirror finish }\end{array}$ & $0.9957 \pm 0.0001$ & $4.5 \mathrm{E}-6 \pm 0.2 \mathrm{E}-6$ & $0.0042 \pm 0.0001$ \\
\hline $\begin{array}{c}13 \% \text { AgTFA:BTDA/ODA } \\
\text { Hazy finish }\end{array}$ & $1.2 \mathrm{E}-5 \pm 0.2 \mathrm{E}-5$ & $0.9993 \pm 0.0007$ & $0.0006 \pm 0.0007$ \\
\hline $5 \%$ Pd:BTDA/ODA & $0.8948 \pm 0.0004$ & $0.0029 \pm 0.0000$ & $0.1023 \pm 0.0003$ \\
\hline $5 \%$ Pd:BTDA/ODA & $0.8837 \pm 0.0006$ & $0.0036 \pm 0.0000$ & $0.1127 \pm 0.0006$ \\
\hline $20.5 \%$ Au:BTDA/4-BDAF & $1.6 \mathrm{E}-5 \pm 0.1 \mathrm{E}-5$ & $0.9992 \pm 0.0010$ & $0.0008 \pm 0.0009$ \\
\hline $20.5 \%$ Au:BTDA/4-BDAF & $1.6 \mathrm{E}-5 \pm 0.1 \mathrm{E}-5$ & $0.9994 \pm 0.0009$ & $0.0006 \pm 0.0009$ \\
\hline $20.5 \%$ Au:CP1 6FDA/4-BDAF & $1.0 \mathrm{E}-5 \pm 0.2 \mathrm{E}-5$ & $0.9993 \pm 0.0010$ & $0.0006 \pm 0.0010$ \\
\hline
\end{tabular}

S11 and S21 plots are shown in Figures 5, 8, 11, and 14; the reverse parameters not shown, S22 and S12, look like the forward parameters for each material. Reflectivity, transmissivity, and emissivity coefficients are shown in Figures $6,9,12$, and 15; Table 3 gives a summary of the power coefficients calculated for all seven samples at 1.414 $\mathrm{GHz}$. These results represent the average of 18 measurements for the $\mathrm{Pd}$ films and 12 for the others. Davisson and Weeks [19] observed that the hemispherical emissivity, an average quantity integrated over all incidence angles, was about 1.2 times the emissivity for normal incidence. Therefore, the emissivity figures derived from L- band VNA measurements, where the incidence angle is $50^{\circ}$, should be conservative, or higher than the normal emissivity.

Silver-The mirror-like silver film shows a thin, but continuous, layer of fine metal particles (Figure 4). Figures 5 and 6 show the film to be 0.9957 reflective with an emissivity of 0.0042 . The hazy film has a large-grained, discontinuous layer in both the TEM and the SEM (Figure 7). Figures 8 and 9 show that film to be almost completely transmissive. 
Palladium-For the palladium films, the TEM shows a thick, continuous metal layer (Figure 10a), whereas the SEM reveals surface fissures (Figure 10b). Previous research has shown continuity between the surface palladium particles, since this layer was highly conductive [20]. As demonstrated by Figures 11 and 12, the Pd films are less reflective and more emissive than the silver films, with reflectivities of 0.8948 and 0.8837 and emissivities of 0.1023 and 0.1127 .

Gold-The TEM of the Au:BTDA/4-BDAF film (Figure 13) shows very large, molar-like particles at the surface and large geometric particles embedded within the polyimide matrix. The large surface particles are evident on the SEM, as well as some very large geometric conglomerates that appear to be just below the surface. In addition, there are holes surrounded by particles appearing similar to eruptions. These holes are seen in the Au:LaRC-CP1 SEM also (Figure 16), while the TEM shows a more continuous layer than the Au:BTDA/4-BDAF. The Au:BTDA/4-BDAF films and the Au:6FDA/4-BDAF (CP1) films behaved similarly when measured with the VNA, all being completely transmissive, as shown in Figures 14 and 15.

\section{OBSERVATIONS AND CONCLUSIONS}

The AgTFA:BTDA/ODA mirror-like film was most successful as an L-band reflector, with 0.9957 reflectivity and 0.0042 emissivity. These figures are in the useful range for reflector antenna applications such as soil moisture measurements. Surprisingly, the AgTFA:BTDA/ODA film with the hazy finish was almost completely transmissive, although its chemical formulation should have been the same. Apparently, an as yet unexplained anomaly had occurred in its fabrication. The Pd:BTDA/ODA films, though similar in appearance to the Ag films, were less reflective and more emissive, having reflectivity around 0.89 and emissivity around 0.11. Therefore, they will probably not be pursued further as L-band reflectors. The Au:BTDA/4-BDAF and Au:6FDA/4-BDAF films were both completely transmissive at L-band, and discontinuous metallization was observed as in past experiments with gold polymers [21]. All of the films had been reflective to light.

The SEM's and TEM's indicated that the more reflective films were characterized by finer grained, smoother, continuous metal surfaces, as in Figure 4. The less reflective or nonreflective films were characterized by coarse (Figure 10), or clumpy, holey metal surfaces (Figures 7, 13, 16). This property of the smoothness of the synthesized metallized polymer was more important than the thickness of the metal in determining its electrical properties; the palladium polymer film was more reflective than the gold polymer, although, in bulk, gold is more reflective.

\section{Quality of the Measurements}

In this series of measurements with the VNA, the power coefficients were characterized with a precision (standard deviation) of 0.0006 or better for highly reflective samples. The results were slightly less precise for highly transmissive samples, the standard deviation being as much as 0.001 . However, the method had been devised with highly reflective materials in mind. As a check for accuracy, an $\mathrm{Al}$ 2024-T6 1/4-in plate and a stainless steel 304 1/8-in plate were measured with the VNA and the resulting emissivities were compared to those calculated from the expected Fresnel coefficient of reflection, given the angle of incidence occurring in the waveguide test fixture and the known conductivities of the metals. The expected emissivity values were 0.0002 for $\mathrm{Al}$ and 0.0008 for stainless steel. The measured emissivity values were 0.0002 \pm 0.0004 for $\mathrm{Al}$ and $0.0012 \pm 0.0002$ for stainless steel, indicating accuracy within 0.0004 for materials with very low emissivity.

\section{Dependence of Emissivity on Frequency}

It was observed that, in all cases where emissivity was measurable, it increased slightly with frequency for a given material (Figures 6b, 12b). The phenomenon was quantified in 1903 by Planck, who used Maxwell's theory to derive the following expression for the reflectivity of a metal, given the DC volume resistivity $\rho$ in ohm-cm, wavelength $\lambda$ in $\mathrm{cm}$, and assuming normal incidence [22], [23].

$$
\begin{gathered}
R_{\lambda}=\frac{\sqrt{3600 \lambda^{2} / \rho^{2}+1}+1-\sqrt{2\left(\sqrt{3600 \lambda^{2} / \rho^{2}+1}-1\right)}}{\sqrt{3600 \lambda^{2} / \rho^{2}+1}+1+\sqrt{2\left(\sqrt{3600 \lambda^{2} / \rho^{2}+1}-1\right)}}( \\
E_{\lambda}=1-R_{\lambda}
\end{gathered}
$$

The theoretically derived expression (11) supported the experimental results of Hagen and Rubens, who had been measuring the optical properties of metals. In 1910 they restated Planck's equation in a series form that made the relationship between emissivity and wavelength very obvious [23].

$$
E_{\lambda}=0.365 \sqrt{\rho / \lambda}-0.0667(\rho / \lambda)+\ldots
$$

This same relationship is obtained by the familiar Fresnel equation for the reflection coefficient $\Gamma$ of a highly conductive, nonmagnetic material at normal incidence.

$$
\begin{gathered}
\Gamma_{\lambda}=\frac{\eta_{\lambda, \text { metal }}-\eta_{\lambda, \text { air }}}{\eta_{\lambda, \text { metal }}+\eta_{\lambda, \text { air }}} \\
E_{\lambda}=1-\left|\Gamma_{\lambda}\right|^{2}
\end{gathered}
$$

\section{FUTURE WORK}

The high reflectivity and low emissivity of the AgTFA film indicate that it should be developed in a space qualified form. More work is required to perfect the synthetic process so that the useful metallized polymers can be produced in a highly repeatable manner. It is of interest to determine the 
quantitative relationship between thickness of the metal layer and conductivity. The VNA measurement technique gave very good results, but more standards are desirable for accuracy assessment throughout the emissivity range of interest, as well as at the low end.

\section{REFERENCES}

[1] R.W. Freeland and G. Bilyeu, "IN-STEP Inflatable Antenna Experiment," Proceedings of the 43rd Congress of the International Astronautical Federation, IAF-92-0301, Washington, DC, 1992.

[2] M.C. Bailey and T.G. Campbell, "Inflatable Tensioned Membrane Waveguide Antenna Array for Space Applications," IUTAM-IASS Symposium on Deployable Structures, Cambridge, UK, Sept. 6-9, 1998.

[3] E. Njoku, W. Wilson, S. Yueh, R. Freeland, R. Helms, W. Edelstein, G. Sadowy, D. Farra, R. West, K. Oxnevad, T. Campbell, W. Lawrence, Y. Rahmat-Samii, H. Feingold, G. Didinsky, J. Rauwolf, M. Thomson, and G. Konicke, "Spaceborne Microwave Instrument for High Resolution Remote Sensing of the Earth's Surface Using a LargeAperture Mesh Antenna," JPL Publication 01-09, Jet Propulsion Laboratory, California Institute of Technology, Sept. 2001.

[4] R.F. Harrington and H.-J.C. Blume, "Determination of Electromagnetic Properties of Mesh Material Using Advanced Radiometer Techniques," Proceedings of the Large Space Antenna Technology Symposium, Dec. 1984.

[5] N. Hubin and L. Noethe, "Active Optics, Adaptive Optics, and Laser Guide Stars," Science, vol. 262, pp. 13901394, Nov. 26, 1993.

[6] K.L. Wilbur, R.J. Jackman, G.M. Whitesides, E.L. Cheung, L.K. Lee, and M.G. Prentiss, Chemistry of Materials, vol. 8, p. 1380, 1996.

[7] K. Ehricke, “The Solar Powered Space Ship," Meeting of the American Rocket Society, ARS Paper 310-356, Cleveland, OH, June 18-20, 1956.

[8] D.A. Gulino, R.A. Egger, and W.F. Banholzer, "Oxidation-Resistant Reflective Surfaces for Solar Dynamic Power Generation in Near Orbit," NASA Technical Memorandum 88865, 1986.

[9] V.B. Huegele, "Thin film deployable reflector model for ET gamma ray imaging telescope system (ET-GRITS)," Reflective Optics II, Proceedings of the Society of Photooptical Instrumentation Engineering, vol. 1113, pp. 79-83, Orlando, FL, Mar. 27-29, 1989.

[10] P.A. Gierow, "Fabrication of Thin Film Concentrators for Solar Thermal Propulsion Applications," Proceedings of the ASME-JSME-JSES Solar Energy Conference, pp. 345351, Reno, NV, 1991.

[11] H.H. Neidlinger and P. Schissel (Eds.), Polymers in Solar Technologies, VCH, Weinheim, pp. 34-51, 1988.

[12] H.H. Neidlinger and P. Schissel, "Photostabilization studies of silver/polymethylmethacrylate films," Optical Materials Technology for Energy Efficiency and Solar Energy Conversion VI, Proceedings of the Society of Photooptical Instrumentation Engineering, vol. 823, pp. 181-189, San Diego, CA, Aug. 18-19, 1987.

[13] G. Jorgensen, and P. Schissel, “Optical Performance and Durability of Silver Polymer Mirrors," K.L. Mittal and J.R. Susko (Eds.), Metallized Plastics I, Plenum Press, New York, pp. 79-92, 1989.

[14] T. Lundeberg, "Prevention of catheter-associated urinary-tract infections by use of silver-impregnated catheters," [letter] Lancet, no. 2, p. 1031, 1986.

[15] R. Gliem and G. Schlamp, "Edelmetalle in der Elektronik," Metallwissenschaft, vol. 41, p. 34, 1987.

[16] P.F. Green and L.L. Berger, Thin Solid Films, vol. 224, p. 209, 1993.

[17] R.L. Cravey, H.-J.C. Blume, C.P. Hearn, M.J. Scherner, L.C. Schroeder, and R.F. Harrington, "Electromagnetic Losses in Metallized Thin Films for Inflatable Radiometer Applications," Proceedings of the AIAA 1995 Space Programs and Technologies Conference, AIAA Paper 95-3741, Huntsville, AL, Sept. 26-28, 1995.

[18] T.J. Wenzel and R.E. Sievers, Analytical Chemistry, vol. 53, no. 3, p. 393, 1981.

[19] C. Davisson and J.R. Weeks, "The Relation Between the Total Thermal Emissive Power of a Metal and Its Electrical Resistivity," Journal of the Optical Society of America and Review of Scientific Instruments, vol. 8, no. 5, pp. 581-606, May 1924.

[20] D.M. Stoakley and A.K. St. Clair, "Synthesis and characterization of self-metallizing palladium-doped polyimide films," Proceedings of the American Chemical Society (ACS) Division of Polymer Chemistry Preprints, vol. 37, no. 1, pp. 541-542, New Orleans, LA, Mar. 24-29, 1996.

[21] M.L. Caplan, D.M. Stoakley and A.K. St. Clair, "Synthesis and Characterization of Self-Metallizing GoldDoped Polyimide Films," Journal of Applied Polymer Science, vol. 56, pp. 995-1006, 1995.

[22] M. Planck, "Uber die optischen Eigenschaften der Metalle fur lange Wellen,” Sitzungsberichte Koeniglichen 
Preussischen Akademie der Wissenschaften, pp. 278-280, 1903.

[23] P. D. Foote, "The Emissivity of Metals and Oxides, Part III: The Total Emissivity of Platinum and the Relation Between Total Emissivity and Resistivity," Bulletin of the Bureau of Standards, vol. 11, pp. 607-612, Nov. 1914.

\section{BIOGRAPHIES}

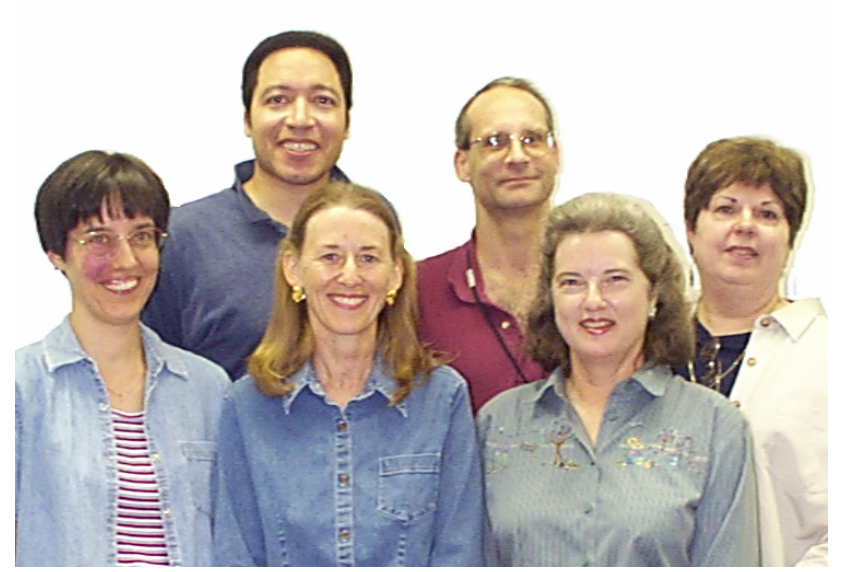

L to R: (Back) Ken Dudley, Dion Fralick, Gilda Miner,

(Front ) Robin Cravey, Anne Mackenzie, Diane Stoakley

Anne I. Mackenzie has a BSEE from Purdue University at Indianapolis and an MSEE degree from Virginia Polytechnical \& State University. She has worked at NASA Langley Research Center since 1987, specializing in radar systems, radiometry, and electromagnetic materials measurements. Her areas of interest have included airborne wind shear detection radar, aircraft wake vortex detection radar, direct radio frequency detection using analog-todigital converters, $\Delta \mathrm{T}$ reduction in radiometers by the use of asymmetrical Dicke-switching, and breast cancer detection using passive radiometry.

Robin Cravey has worked at NASA Langley Research Center for 11 years. Her research interests include electromagnetic properties of materials, and she has been the lead engineer in the Electromagnetic Properties Measurements Laboratory since its inception in the early 1990s. She has authored/co-authored 7 publications in the area of electromagnetic properties measurements. Other areas of interest are large, lightweight space antennas and computational electromagnetics. She has a Ph.D. in physics from the Georgia Institute of Technology.
Kenneth Dudley has been a NASA researcher since 1986, when he started as a co-op student. He attended the United States Air Force Academy in Colorado Springs from 1982 to 1984. He received an AAS degree in electronics technology from Thomas Nelson Community College in 1987, graduated from the NASA Apprentice Program in 1991, and continued coursework in electrical engineering at the Peninsula Graduate Center in Hampton, VA. His expertise is in radio frequency spectrum and network analysis, and his area of research includes antennas, radar cross section, high intensity radiated fields (HIRF), and electromagnetic materials. He has worked on both space and airborne projects in electromagnetics and was a special team member on the NTSB investigation into the crash of TWA Flight-800.

Dion Fralick is a senior research engineer at NASA Langley Research Center, where he has been employed for the last three years. For the previous nine years he was employed by Lockheed-Martin providing engineering consultation to NASA LaRC in the area of electromagnetic measurements. Mr. Fralick also spent eight years in the United States Air Force. He has authored/co-authored 12 publications in various electromagnetic measurement areas. Mr. Fralick holds an MSEE and BSEE from Ohio University and a BSET from the University of North Carolina at Charlotte.

Polymer Group: Diane Stoakley and Gilda Miner are senior chemists in the Structures and Materials Competency at NASA Langley Research Center. Both Ms. Stoakley and Ms. Miner have been employed at Langley for more than 22 years. Ms. Stoakley is the group leader of Langley's Advanced Films and Coatings Group of which Ms. Miner is a member. The AF\&C Group is involved in the development of thermally stable, electrically tailored polymer films and flexible polyimides with highly reflective surfaces for applications including solar concentrators and mirrors. Their research includes the development of new polymeric materials for advanced aircraft applications and high performance thin films and coatings for improved durability in the space environment, concentrating in the area of self-metallization of thermally stable, electrically tailored, and flexible polymer films with uniformly distributed metal nanoparticulates with highly reflective surfaces for solar concentrators, mirrors and antennas or without surface metallization for obtaining passivated nanoparticulates. Ms. Stoakley is the author/co-author of 26 publications and holds 18 U.S. and foreign patents. Ms. Miner is the author/co-author of 11 publications. 